\title{
From the other side of the fence
}

\author{
Derek Wooff
}

"I think she'll have to come into hospital." Until that point I suppose I had half hoped that my 9 week old daughter really wasn't unwell, but secretly I was relieved that she was being admitted to a centre of excellence and much of the responsibility was being removed from my shoulders. It had all started with a typical snuffly cold that had been initially ignored and then treated by raiding the samples in the surgery and giving her a week's course of Ceporex. Feeling reassured by the undoubted magic of antibiotics we headed en masse to my in laws. There it became obvious that things were not improving and a worsening cough and pyrexia persuaded us to call in an independent expert in the guise of the local general practitioner. He confirmed a chest infection and prescribed a course of erythromycin.

Over the next couple of days we alternated between feeling that she was getting better to trying to decide if she had central cyanosis. Eventually I decided that a tachypnoea of 70 , poor feeding, and a distressing cough would cause me to seek hospital admission for one of my own patients and I could do no less for my own daughter. It was a relief to stop pretending that we thought she was getting better and to have made a definitive decision to seek the help of the specialist. When we called him back the general practitioner agreed and packed us off to the local paediatric hospital.

We had elected to go to a specialised paediatric hospital rather than to a general hospital with a paediatric department, so we had to report to the accident and emergency department for the initial assessment. The clerkess was not impressed by my medical title and declined my diagnosis of chest infection, telling me that the doctor would decide. The attendant nursing staff were also not impressed by the obvious respiratory distress of my child and we had to sit and wait for half an hour before achieving the first hurdle of getting into an examination cubicle. This was particularly poignant because as soon as we had made the decision that hospital admission was required we had rushed to the casualty department as fast as possible. To then have our progress hampered by the machinery of assessment produced a degree of irritation.

Three hours later my daughter had had a chest $x$ ray examination and her second medical examination, which confirmed a diagnosis of bronchiolitis. At long last we reached the sanctuary of the paediatric ward. Thankfully blood gases showed that there was no hypoxia and much of our immediate anxiety was allayed. As she was breast feeding my wife decided to stay with my daughter and they were given a mother and baby cubicle with sink, shower, and the sleep defeating starched sheet covered bed. After a stormy 24 hours my daughter progressed rapidly to a full recovery.

Despite a typical medical education and four years as a principal in general practice, I was unprepared and ignorant of many of the difficulties that our patients face. I have now learnt how impersonal large hospitals are despite every effort of the staff, purely because of the organisation needed to deal with a large number of patients. I can now understand the frustration of being kept waiting for a long time when there is no obvious reason. Time passes particularly slowly when we are worried and patience is perhaps more easily achieved if we are kept informed of why there are delays. I was disappointed that a purpose built modern paediatric hospital lacked so many small details which would have helped worried parents, especially the live in mums. There were only three public telephones for the whole hospital, producing the unpleasant sight of disressed mothers queuing to speak to their husbands. Meals had to be taken in the hospital canteens at official meal times and no provision was made for those unable to leave their sick child. The rooms were too hot and excessively noisy, meaning that as the children improved the mothers slipped into a state of chronic exhaustion. Although the children are the main concern on these wards, I am sure that their recovery is enhanced by the presence of their mothers at a time when they feel at their most vulnerable, and more consideration needs to be given to the mothers.

Doctors' families tend to be undertreated or overtreated leading usually to less than ideal medical care. As first of all an anxious parent and only secondly a doctor I was delighted by the consultant's manner. He explained his intentions, dispelled our mainly neurotic fears, and when asked gave objective and definitive advice. In short, he was the perfect specialist and doctor. He combined knowledge and experience with patience and compassion.

I think that most of us unconsciously feel immune to the trauma of ill health as experienced by our patients. Illness is something that happens to other people and we as doctors are there to help them as best we can. Personal experience of the worry and stress of illness in our own families can teach us many things and must help make us better doctors. Derek Wooff is a general practitioner from Stranraer

\section{ANY QUESTIONS}

How should the treatment of hypothyroidism with thyroxine sodium be monitored?

It is well recognised that many hypothyroid patients receiving thyroxine replacement treatment have raised serum thyroxine concentrations and yet the concentrations of the metabolically active hormone triiodothyronine are normal. Such patients are generally found to be clinically euthyroid. The average daily requirement of thyroxine for hypothyroid patients is 150 $\mu \mathrm{g}$ daily.' In more than half of the patients receiving this dose the serum thyroxine concentration is above the normal range. ${ }^{2}$ It is uncertain whether this matters. A suppressed thyroid stimulating hormone concentration may not necessarily imply overtreatment as its level is determined by the serum thyroxine concentration, so it will tend to be suppressed by raised serum thyroxine concentrations in the presence of a normal serum triiodothyronine concentration.

There are those who regard biochemical tests of thyroid function as of little if any value in monitoring patients receiving thyroxine replacement. ${ }^{3}$ I think, however, that we should be wary of this policy. Hyperthyroidism and hypothyroidism each cover a wide range of thyroid function and clinical diagnosis of mild cases may be difficult. Furthermore, it is not known whether the cardiac complications of florid thyrotoxicosis such as atrial fibrillation, cardiomyopathy, and ventricular fibrillation occur in subclinical cases. There is therefore a place for biochemical tests in treated hypothyroidism. If the serum thyroid stimulating hormone concentration is raised the replacement treatment is inadequate. If the serum free triiodothyronine concentration is raised the dose is excessive. If the serum thyroxine concentration is raised but the thyroid stimulating hormone concentration is not suppressed the dose is probably correct. If the serum thyroxine concentration is raised and the thyroid stimulating hormone concentration suppressed it is probably wise to attempt to reduce the replacement dose. - C W H HAVARD, consultant physician and endocrinologist, London

1 Evered D, Young ET, Ormston BJ, et al. Treatment of hypothyroidism: reappraisal of thyroxine therapy. BrMed f 1973;iii:131-4.

2 Ingbar JCl, Borges $M$, Iflah $\mathrm{S}$, et al. Elevated serum $\mathrm{T} 4$ concentrations in patients receiving replacement doses of thyroxine. $\mathcal{F}$ Endocrinol 1982;5:77-85.

Fraser WD, Biggart EM, O'Reilly DSJ, et al. Are biochemical tests of thyroid function of any value in monitoring patients receiving thyroxine replacement? $\mathrm{Br} M e d \mathcal{F}$ 1986;293:808-10. 